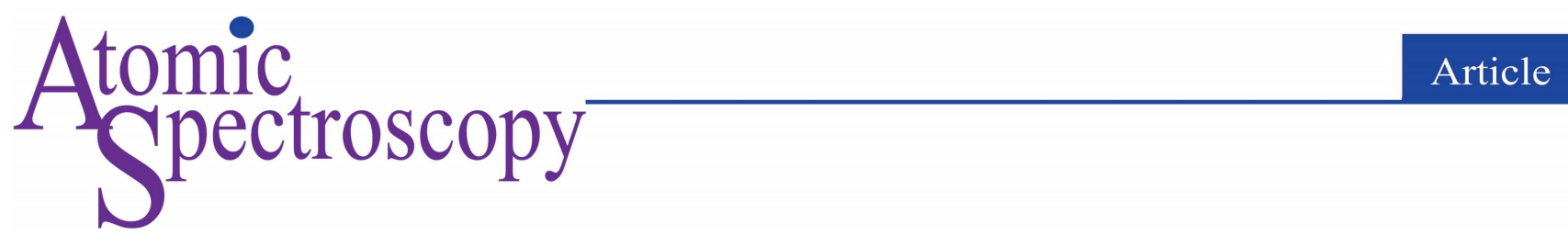

\title{
An Isotopic Study of Bio-accessible Lead in Wheat, Miswak Toothbrush and Miswak Fruit Using the Continuous On-line Leaching Method with Inductively Coupled Plasma Mass Spectrometry
}

\author{
Randa A. Althobiti and Diane Beauchemin* \\ Queen's University, Department of Chemistry, 90 Bader Lane, Kingston, ON K7L 3N6, Canada
}

Received: July 14, 2021; Revised: July 27, 2021; Accepted: July 30, 2021; Available online: July 31, 2021.

DOI: $10.46770 / A S .2021 .708$

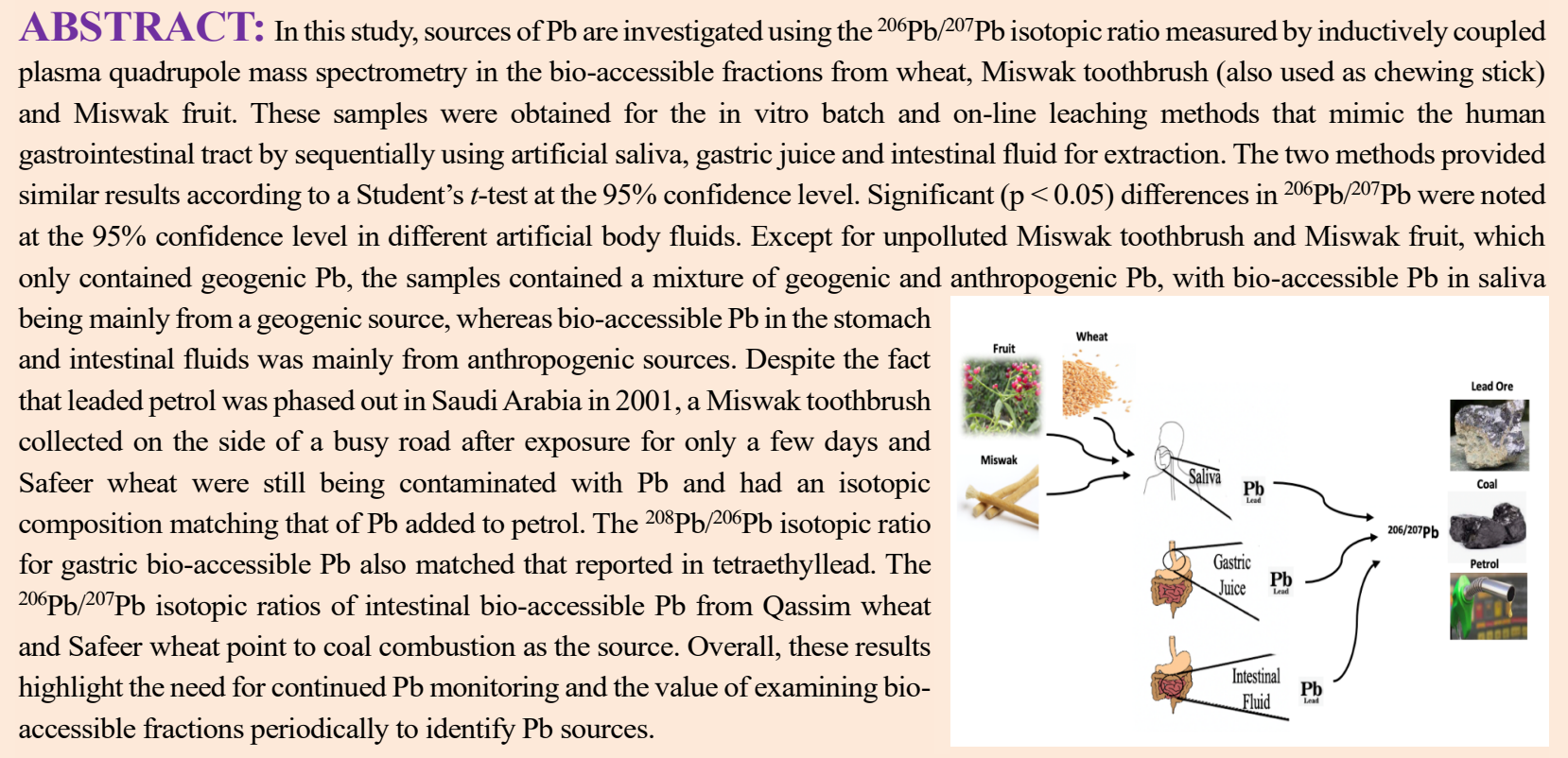

\section{INTRODUCTION}

Lead contamination of the environment as a result of human activities is a pervasive and serious problem. ${ }^{1}$ The wide range of anthropogenic activities involving the release of this metal often makes source identification of $\mathrm{Pb}$ necessary in order to plan effective abatement strategies for contaminated sites. ${ }^{1}$

Lead is naturally ubiquitous in water, air and soil. However, additional sources of $\mathrm{Pb}$ in the atmosphere are caused due to mining activities, burning of coal, smelting, non-ferrous metal refining, waste incineration and combustion of gasoline containing
$\mathrm{Pb}$ as anti-knock agent. As a result, $\mathrm{Pb}$ accumulates in plants and eventually enters the gastrointestinal tract via ingestion and inhalation, where the bio-accessible portion (released in the gastrointestinal tract) may become bio-available (enter the circulatory system) and cause toxic effects. ${ }^{2-5}$

In nature, $\mathrm{Pb}$ has four stable isotopes: ${ }^{204} \mathrm{~Pb}(1 \%),{ }^{206} \mathrm{~Pb}(24 \%)$, ${ }^{207} \mathrm{~Pb}(23 \%)$ and ${ }^{208} \mathrm{~Pb}(52 \%)$. The latter three are formed from the radioactive decay of $U$ and $T h$. Indigenous variation in stable isotope composition can thus be used to identify the $\mathrm{Pb}$ sources. ${ }^{6-7}$ The isotopic composition of $\mathrm{Pb}$ in environmental samples can reflect and help discriminate the $\mathrm{Pb}$ source. ${ }^{8}$ This fingerprinting 
approach is a valuable tool for tracing $\mathrm{Pb}$ in the environment. ${ }^{9}$

Over the years, there has been a significant improvement in controlling $\mathrm{Pb}$ concentrations in the environment, such as phasing out leaded gasoline in accordance with the ruling of the World Health Organization (WHO).$^{10}$ Yet, $\mathrm{Pb}$ is still classified as the second most hazardous substance, after only As, as reported by the Agency for Toxic Substances and Disease Registry. ${ }^{11}$ In Saudi Arabia, despite phasing out leaded gasoline in $2001, \mathrm{~Pb}$ continues to accumulate in the environment ${ }^{11}$ and still exceeds the $0.2-0.3$ $\mathrm{mg} \mathrm{Pb} \mathrm{kg}{ }^{-1}$ food regulation in the region. ${ }^{12-16}$

Lead isotope ratios are commonly measured using thermal ionization mass spectrometry, multi-collector inductively coupled plasma mass spectrometry (MC-ICP-MS) and inductively coupled plasma quadrupole mass spectrometry (ICP-QMS). Whereas TIMS and MC-ICP-MS are preferred methods for geological dating applications, ICP-QMS is widely used for environmental source studies. In contrast to TIMS and MC-ICP$\mathrm{MS}$, it is relatively inexpensive and requires minimal sample preparation while allowing sufficiently precise $\mathrm{Pb}$ isotope ratio measurements. ${ }^{5,17-19}$

To assess and identify the $\mathrm{Pb}$ exposure pathways, $\mathrm{Pb}$ isotope ratios can be measured in blood samples. For example, the $\mathrm{Pb}$ isotope ratios in children's blood were reported to match those in soil and house dust, suggesting their ingestion as the source of $\mathrm{Pb}$ in blood. ${ }^{20}$ Similarly, the $\mathrm{Pb}$ isotopic composition in children's blood in China corresponded to that found in the ash of coal combustion and particulate matter. This suggests that the inhalation of these air particulates from coal ash, contaminated during coal combustion, was a significant contributor to $\mathrm{Pb}$ in their blood. ${ }^{21}$ In another case, the $\mathrm{Pb}$ isotope ratios in children's blood agreed with those found in the vegetables, wheat, drinking water, and air particulates from the local areas, suggesting that dietary and inhalation pathways were the most likely sources for these children's $\mathrm{Pb}$ in blood. ${ }^{22}$

An alternative to measuring bio-available $\mathrm{Pb}$ isotope ratios is to determine $\mathrm{Pb}$ isotope ratios in the bio-accessible fraction, which circumvents the above difficulties. Given that the bio-accessible fraction $^{24}$ is equal to the bio-available fraction in the worst-case scenario, $\mathrm{Pb}$ isotope ratios may thus be measured in the bioaccessible fraction of environmental samples to realistically estimate the main $\mathrm{Pb}$ contamination sources.

The continuous on-line leaching method, where gastrointestinal reagents are sequentially pumped through a minicolumn of sample while the effluent is continuously monitored by ICP-QMS, allows bio-accessibility measurements in a fraction of the time required for batch methods because continuous exposure of the sample to fresh reagents shifts the dissolution equilibrium to the right. ${ }^{24}$ In addition, it provides real-time information that can help discriminate different sources. ${ }^{24}$ It revealed two sources of $\mathrm{Pb}$ being released in gastric juice from corn bran, i.e., two peaks in the temporal profile, where one peak showed a $\mathrm{Pb}$ isotopic composition matching that of tetraethyllead (TEL) previously added to gasoline as the anti-knock agent. ${ }^{25}$

Given the problematic $\mathrm{Pb}$ levels in Saudi Arabia, in addition to $\mathrm{Pb}$ up to $100 \%$ bio-accessible from wheat, ${ }^{15}$ Miswak natural toothbrush (also used as a chewing stick) ${ }^{26}$ and Miswak fruit, ${ }^{26}$ source apportionment would be useful. For instance, if most of the $\mathrm{Pb}$ is anthropogenic, actions can then be taken to reduce contamination. The aim of this research was to investigate the isotopic composition of bio-accessible $\mathrm{Pb}$ from these samples. The results obtained by a conventional batch method to measure bio-accessibility were compared to those obtained by the on-line leaching method previously developed. ${ }^{24}$ The resulting $\mathrm{Pb}$ isotopic composition was then compared to that reported in the literature to identify the most probable source(s) of $\mathrm{Pb}$ in wheat, Miswak toothbrush and Miswak fruit from Saudi Arabia. To the best knowledge of the authors, $\mathrm{Pb}$ source apportionment has never been conducted on such samples.

\section{EXPERIMENTAL}

Instrumentation. Lead isotope ratio measurement was performed using a Varian 820MS ICP-QMS (Varian Inc., Mulgrave, Victoria, Australia), with Bruker Quantum software. The instrument was equipped with a Burgener Mira Mist nebulizer (Burgener Research, Mississauga, ON, Canada) inserted into a Scott doublepass spray chamber (SCP Science, Baie d'Urfé, QC, Canada) and a collision-reaction interface (CRI). To maintain $\mathrm{CeO}^{+} / \mathrm{Ce}^{+}<2 \%$ and $\mathrm{Ba}^{++} / \mathrm{Ba}^{+}<2 \%$, the instrument was tuned daily using $5 \mu \mathrm{g} \mathrm{L}^{-1}$ $\mathrm{Be}, \mathrm{Mg}, \mathrm{Co}, \mathrm{In}, \mathrm{Ce}, \mathrm{Pb}$ and $\mathrm{Ba}$ in $2 \%$ (v/v) $\mathrm{HNO}_{3}$. The operating conditions are summarized in Table 1. Data acquisition was performed in the steady-state mode with $10 \mathrm{~s}$ integration for the batch method and in time-resolved mode for the on-line leaching method, with three points per peak, one scan per replicate, a dwell time of $80 \mathrm{~ms}$ and 0.025 a.m.u. spacing.

Samples. Saudi Arabia is located in Western Asia and is geographically the largest state in the Middle East. Wheat samples in this study were purchased from grocery stores in the Western province of Saudi Arabia. As shown in Fig. 1, they originated from

Table 1. ICP-QMS (Varian 820MS) Operating Conditions

\begin{tabular}{ll}
\hline Parameter & Setting \\
\hline Ar plasma gas flow rate & $18.0 \mathrm{~L} \mathrm{~min}^{-1}$ \\
Ar auxiliary gas flow rate & $1.80 \mathrm{~L} \mathrm{~min}^{-1}$ \\
Ar nebulizer flow rate & $1.05 \mathrm{~L} \mathrm{~min}^{-1}$ \\
Sample uptake rate & $0.8 \mathrm{~mL} \mathrm{~min}$ \\
Sampling position & $6.2 \mathrm{~mm}$ \\
Ar sheath gas flow rate & $0.06 \mathrm{~L} \mathrm{~min}$ \\
Radio-frequency Power & $1.40 \mathrm{~kW}$ \\
CRI skimmer $\mathbf{H}_{2}$ gas flow rate & $85 \mathrm{~mL} \mathrm{~min}^{-1}$ \\
Monitored signals & ${ }^{206} \mathrm{~Pb}^{+},{ }^{207} \mathrm{~Pb}^{+},{ }^{208} \mathrm{~Pb}^{+}$ \\
\hline
\end{tabular}




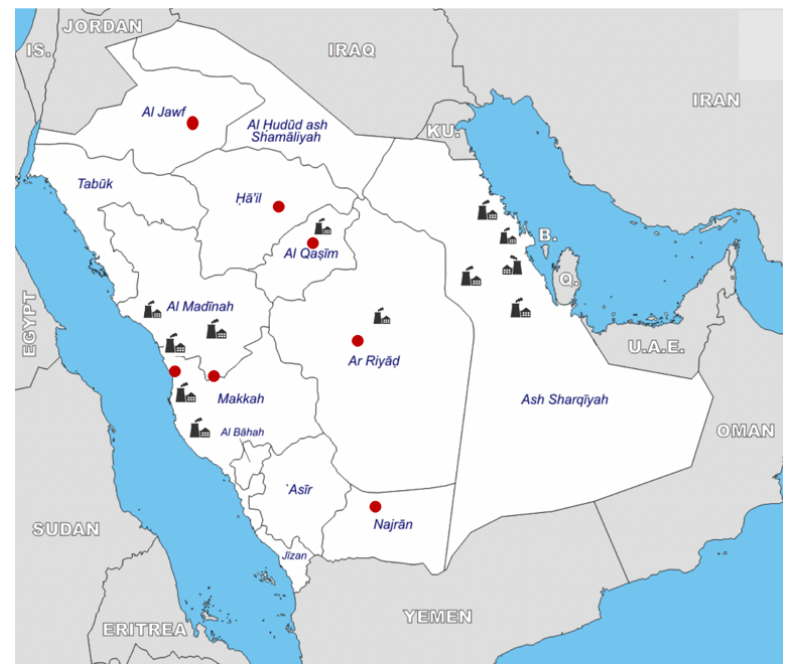

Fig. 1 Map of Saudi Arabia with sample sources in red. Industry signs indicate sites of major industries. ${ }^{27}$

different regions: Northern (Dubai), Western (Nakleeh), SouthWestern (Najran) and Central Arabia (Noqrah, Qassim and Safeer). All-natural toothbrush and Miswak's fruits were collected from one Miswak tree (Salvadora persica) in Al Lith city, located on the coast of the Red Sea (Western province).

The Miswak toothbrushes were 30-cm long, with a 1-cm diameter. Unpolluted Miswak toothbrushes and Miswak fruits were collected from one Miswak tree and placed directly in separate polyethylene bags upon collection, whereas polluted Miswak toothbrushes were sampled from the same Miswak tree but handled normally and transported for $180 \mathrm{~km}$ to Jeddah city to be sold in an open market on the roadside of a busy street. After a few days, one Miswak toothbrush was placed in a polyethylene bag for later analysis. Then, these samples were ground by hand to a fine powder with a porcelain pestle and mortar and kept in polyethylene bags at $4^{\circ} \mathrm{C}$ until analysis.

Reagents. Artificial saliva was prepared by mixing $6.8 \mathrm{~g}$ of $\mathrm{KH}_{2} \mathrm{PO}_{4}$ (ACS grade; Fisher Scientific, Ottawa, ON, Canada) and $77 \mathrm{~mL}$ of $0.2 \mathrm{~mol} \mathrm{~L}^{-1} \mathrm{NaOH}$ (ACS grade; BioShop, Burlington, $\mathrm{ON}$, Canada). After adjusting the $\mathrm{pH}$ to 6.5 with $0.2 \mathrm{~mol} \mathrm{~L}^{-1} \mathrm{NaOH}$, the sample was diluted to $1 \mathrm{~L}$ with doubly deionized water (DDW) (Arium Pro UV|DI, Sartorius Stedim Biotech, Göttingen, Germany).

For preparation of gastric juice (pH. 1.2), $2.0 \mathrm{~g}$ of $\mathrm{NaCl}$ (ACS grade; BioShop), $3.2 \mathrm{~g}$ of pepsin (Sigma-Aldrich, Oakville, ON, Canada) and $7.0 \mathrm{~mL}$ of sub-boiled $\mathrm{HCl}$ (ACS grade; Fisher Scientific) were combined, then diluted to $1 \mathrm{~L}$ with DDW.

Intestinal fluid was prepared by mixing $6.8 \mathrm{~g}$ of $\mathrm{KH}_{2} \mathrm{PO}_{4}, 10 \mathrm{~g}$ of pancreatin (Sigma-Aldrich, St. Louis, MO, USA) and $77 \mathrm{~mL}$ of $0.2 \mathrm{~mol} \mathrm{~L}^{-1} \mathrm{NaOH}$, then diluting to $1 \mathrm{~L}$ with DDW after adjusting the $\mathrm{pH}$ to 6.8 with $0.2 \mathrm{~mol} \mathrm{~L}^{-1} \mathrm{NaOH}$.
All acids were purified using a DST-1000 sub-boiling distillation system (Savillex, Minnetonka, MN, USA).

Batch method. Approximately $1 \mathrm{~g}$ of sample was placed in a 50 $\mathrm{mL}$ falcon tube with artificial saliva. The test tube was then placed in a shaker for $10 \mathrm{~min}$ at $37^{\circ} \mathrm{C}$ to mimic human body temperature. Then, the tube was centrifuged for $15 \mathrm{~min}$ at $4100 \mathrm{rpm}$ and $3^{\circ} \mathrm{C}$. The supernatant was decanted, filtered, and collected in a clean bottle (high-density polyethylene). The same procedure was repeated with artificial gastric juice and finally intestinal juice, each shaken for $2 \mathrm{~h}$.

On-line leaching method. An amount of $0.4 \mathrm{~g}$ of ground sample was rolled in glass wool and then inserted into a mini-column (5$\mathrm{cm}$ long polytetrafluoroethylene tube with $5 / 16$-in outer diameter and 1/4-in inner diameter). A clean glass wool plug was placed at each end of the mini-column to trap the sample, maximize the flow and minimize clogging. The ICP-QMS instrument's peristaltic pump controlled the flow rate of the artificial body fluids that were sequentially pumped through the mini-column to the nebulizer. A thermostatically controlled water bath (Haake, Berlin, Germany) maintained the mini-column and gastro-intestinal reagents at $37^{\circ} \mathrm{C}$.

Data processing. For the batch method, the $\mathrm{Pb}$ isotope ratios were readily obtained by dividing the average steady-state signal of ${ }^{206} \mathrm{~Pb}^{+}$by that of ${ }^{207} \mathrm{~Pb}^{+}$. For the transient signal resulting from the on-line method, the point-by-point signal intensity of ${ }^{206} \mathrm{~Pb}^{+}$was plotted versus ${ }^{207} \mathrm{~Pb}^{+}$using Microsoft Office Excel 2016. This yielded a straight line whose slope was the ${ }^{206} \mathrm{~Pb} /{ }^{207} \mathrm{~Pb}$ isotope ratio. This approach was reported to provide more accurate ratios than a ratio of peak areas or the average point-by-point ratio. ${ }^{28}$ The same approach was used to obtain the ${ }^{208} \mathrm{~Pb} /{ }^{206} \mathrm{~Pb}$ isotope ratio to confirm TEL as a source.

To compare the results from the on-line and batch methods, an F test was first performed at the $95 \%$ confidence level to determine if there was a significant difference in variance. The appropriate Student's $t$-test was then performed at the $95 \%$ confidence level to establish if there was a significant difference between the results. To compare leaching of the three gastro-intestinal reagents, analysis of variance (ANOVA) was conducted: a significant difference $(\mathrm{p}<0.05)$ between the $\mathrm{Pb}$ isotope ratios by the two methods for a given leaching reagent indicates that there is at least one source significantly different from the others. Tukey Pairwise analysis was then conducted to reveal which $\mathrm{Pb}$ source in the body fluids was significantly different.

\section{RESULTS AND DISCUSSION}

${ }^{206} \mathrm{~Pb} /{ }^{207} \mathrm{~Pb}$ isotope ratio in bio-accessible fraction from wheat. Fingerprinting based on the ${ }^{206} \mathrm{~Pb} /{ }^{207} \mathrm{~Pb}$ isotope ratio is commonly used to distinguish anthropogenic $\mathrm{Pb}$ input from that of natural origin in environmental samples. ${ }^{29}$ The ratios measured in the bioaccessible fraction from the wheat samples in each artificial 
Table 2. ${ }^{206} \mathrm{~Pb} /{ }^{207} \mathrm{~Pb}$ Ratios \pm Standard Deviation (\% relative standard deviation (\% RSD)) Measured in Saliva, Gastric Juice and Intestinal Fluid Leachates from Wheat Samples by On-line Continuous Leaching and Batch Methods, with Student's $t$-test at the 95\% Confidence level $(n=3-5)$

\begin{tabular}{|c|c|c|c|c|c|}
\hline \multirow{2}{*}{ Region } & \multirow{2}{*}{$\begin{array}{c}\text { Leaching } \\
\text { reagent }\end{array}$} & \multirow{2}{*}{ Method } & \multirow{2}{*}{$\begin{array}{c}\text { Pb ratio }( \pm \text { SD) } \\
\text { (RSD) }\end{array}$} & \multicolumn{2}{|c|}{ Student's $t$} \\
\hline & & & & Found & Table \\
\hline \multirow{6}{*}{ Dubai } & \multirow{2}{*}{ Saliva } & Batch & $1.14 \pm 0.02(2)$ & \multirow{2}{*}{1.54} & \multirow{2}{*}{3.18} \\
\hline & & On-line & $1.12 \pm 0.01(1)$ & & \\
\hline & & Batch & $1.08 \pm 0.10(9)$ & \multirow{2}{*}{0.66} & \multirow{2}{*}{2.36} \\
\hline & Jasuic jure & On-line & $1.05 \pm 0.03(3)$ & & \\
\hline & \multirow{2}{*}{ Intestinal fluid } & Batch & $1.11 \pm 0.03$ (3) & \multirow{2}{*}{2.43} & \multirow{2}{*}{2.45} \\
\hline & & On-line & $1.06 \pm 0.03(3)$ & & \\
\hline \multirow{6}{*}{ Nakleeh } & \multirow{2}{*}{ Saliva } & Batch & $1.14 \pm 0.03$ (3) & \multirow{2}{*}{0.23} & \multirow{2}{*}{2.45} \\
\hline & & On-line & $1.15 \pm 0.02(2)$ & & \\
\hline & \multirow{2}{*}{ Gastric juice } & Batch & $1.06 \pm 0.08(7)$ & \multirow{2}{*}{0.63} & \multirow{2}{*}{2.36} \\
\hline & & On-line & $1.03 \pm 0.07(7)$ & & \\
\hline & \multirow{2}{*}{ Intestinal fluid } & Batch & $1.07 \pm 0.08(7)$ & \multirow{2}{*}{0.49} & \multirow{2}{*}{2.44} \\
\hline & & On-line & $1.05 \pm 0.04(4)$ & & \\
\hline \multirow{6}{*}{ Qassim } & \multirow{2}{*}{ Saliva } & Batch & $1.08 \pm 0.06(5)$ & \multirow{2}{*}{0.74} & \\
\hline & & On-line & $1.06 \pm 0.02(2)$ & & $2.7 \mathrm{~T}$ \\
\hline & Gastric iuice & Batch & $1.19 \pm 0.11(9)$ & 038 & 236 \\
\hline & & On-line & $1.17 \pm 0.03$ (3) & 0.00 & \\
\hline & & Batch & $1.17 \pm 0.20(17)$ & & \\
\hline & 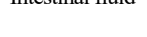 & On-line & $1.16 \pm 0.02(2)$ & 0.29 & 2.11 \\
\hline & Solive & Batch & $1.14 \pm 0.03$ (3) & 125 & 15. \\
\hline & Salliva & On-line & $1.15 \pm 0.03(3)$ & 1.20 & $2.4 \mathrm{~J}$ \\
\hline & & Batch & $1.05 \pm 0.05(5)$ & & \\
\hline Najran & Gastric Juice & On-line & $1.05 \pm 0.03$ (3) & 0.07 & 2.31 \\
\hline & & Batch & $1.08 \pm 0.04(4)$ & & \\
\hline & Intestinal fluid & On-line & $1.04 \pm 0.04$ (4) & 1.52 & 2.36 \\
\hline & Selim & Batch & $1.08 \pm 0.30(27)$ & 008 & \\
\hline & Sarrva & On-line & $1.02 \pm 0.07(7)$ & 0.00 & 2.07 \\
\hline Nograh & Gastric iuice & Batch & $1.03 \pm 0.08(8)$ & 0.08 & 245 \\
\hline & & On-line & $1.03 \pm 0.04(4)$ & & \\
\hline & & Batch & $1.09 \pm 0.05(5)$ & & \\
\hline & пісынап пй & On-line & $1.01 \pm 0.06(6)$ & 2.20 & 2.00 \\
\hline & & Batch & $1.12 \pm 0.02(2)$ & & \\
\hline & Sallva & On-line & $1.13 \pm 0.05$ (4) & 0.20 & 2.43 \\
\hline & & Batch & $1.20 \pm 0.09(8)$ & & \\
\hline Safeer & Gastric juice & On-line & $1.21 \pm 0.02(2)$ & 0.04 & 2.57 \\
\hline & & Batch & $1.16 \pm 0.02(2)$ & & \\
\hline & mestrinal ritura & On-line & $1.17 \pm 0.02(2)$ & 0.48 & 2.11 \\
\hline
\end{tabular}

leaching reagent by the conventional batch method were compared to those with the on-line leaching method, as listed in Table 2. The results are in agreement based on the Student's $t$-test at the $95 \%$ confidence level, confirming similar results by the two methods. However, the precision, expressed as relative standard deviation (RSD), for the ratios by the on-line method was in general better than by the batch method. Indeed, the $2-7 \%$ range with the on-line method is clearly narrower than the $2-27 \%$ range with the batch method.

The $\mathrm{Pb}$ released from the wheat samples obtained from Dubai, Nakleeh, Najran and Safeer has an isotopic composition that falls within the 1.12-1.15 range previously reported for geogenic $\mathrm{Pb}$, i.e., indigenous $\mathrm{Pb}$ ores in Saudi Arabia. ${ }^{30} \mathrm{The}{ }^{206} \mathrm{~Pb} / 207 \mathrm{~Pb}$ isotope ratio in saliva was found to be significantly different from those in gastric juice and intestinal fluid $(\mathrm{p}<0.05)$ at the $95 \%$ confidence level.

China and Indonesia were major providers of coal to Saudi Arabia during the last three decades of the 20th century, which had a ${ }^{206} \mathrm{~Pb} /{ }^{207} \mathrm{~Pb}$ isotope ratio in the $1.15-1.18$ range. ${ }^{31-32}$ The $\mathrm{Pb}$ released by intestinal fluid from the wheat from Qassim and Safeer has an isotopic composition that falls within this range, indicating that coal burning may be responsible for this more radiogenic $\mathrm{Pb}$. In each case, the isotopic ratio is significantly different from that in saliva $(\mathrm{p}<0.05)$ at the $95 \%$ confidence level. There is also evidence of $\mathrm{Pb}$ from leaded gasoline $\left({ }^{206} \mathrm{~Pb} /{ }^{207} \mathrm{~Pb} \text { of } 1.21\right)^{33}$ in the gastric juice leachate from Safeer wheat, indicating that the soil contamination from decades of leaded petrol use in that region is still reflected in wheat.

The lower isotope ratios in gastric juice and intestinal fluid leachates of wheat from Dubai, Nakleeh and Najran compared to geogenic $\mathrm{Pb}$, is likely a result of industrial $\mathrm{Pb}$ emissions, e.g., from copper smelters. ${ }^{34}$ The different geographical origins of these samples (North, West and Southern-West, respectively) suggest atmospheric transport of anthropogenic $\mathrm{Pb}$. Storms are well known to occur in those regions, which carry large amounts of particulate matter over long distances. ${ }^{35}$

The similarity or difference between sources of $\mathrm{Pb}$ are also evident when plotting the temporal leaching profile of $\mathrm{Pb}$ versus that of $\mathrm{Cd}$, which was recently used to help visualize different sources of these elements in Miswak. ${ }^{16}$ For example, Fig. 2 shows very different correlations between the temporal profiles of $\mathrm{Pb}$ and $\mathrm{Cd}$ for two wheat samples (from Noqrah and Safeer) that contained similar concentrations of $\mathrm{Pb}\left(2000 \pm 520 \mu \mathrm{g} \mathrm{kg}^{-1}\right.$ and $2000 \pm 400 \mu \mathrm{g} \mathrm{kg}^{-1}$ respectively). ${ }^{15}$ The less bio-accessible $\mathrm{Pb}$ in Noqrah wheat ${ }^{15}$ seems to be from a single source, supporting the similar ${ }^{206} \mathrm{~Pb} /{ }^{207} \mathrm{~Pb}$ isotopic ratio in saliva, gastric juice and intestinal fluid. In contrast, three different sources are clearly indicated by the three different correlations between $\mathrm{Pb}$ and $\mathrm{Cd}$ for Safeer wheat (Fig. 2), in agreement with the significantly different isotopic ratios in each of the three gastro-intestinal reagents.

${ }^{206} \mathrm{~Pb} /{ }^{207} \mathrm{~Pb}$ isotope ratio in bio-accessible fraction from Miswak toothbrush and Miswak fruit. Table 3 shows the ${ }^{206} \mathrm{~Pb} /{ }^{207} \mathrm{~Pb}$ isotopic ratios obtained in the saliva, gastric juice and 

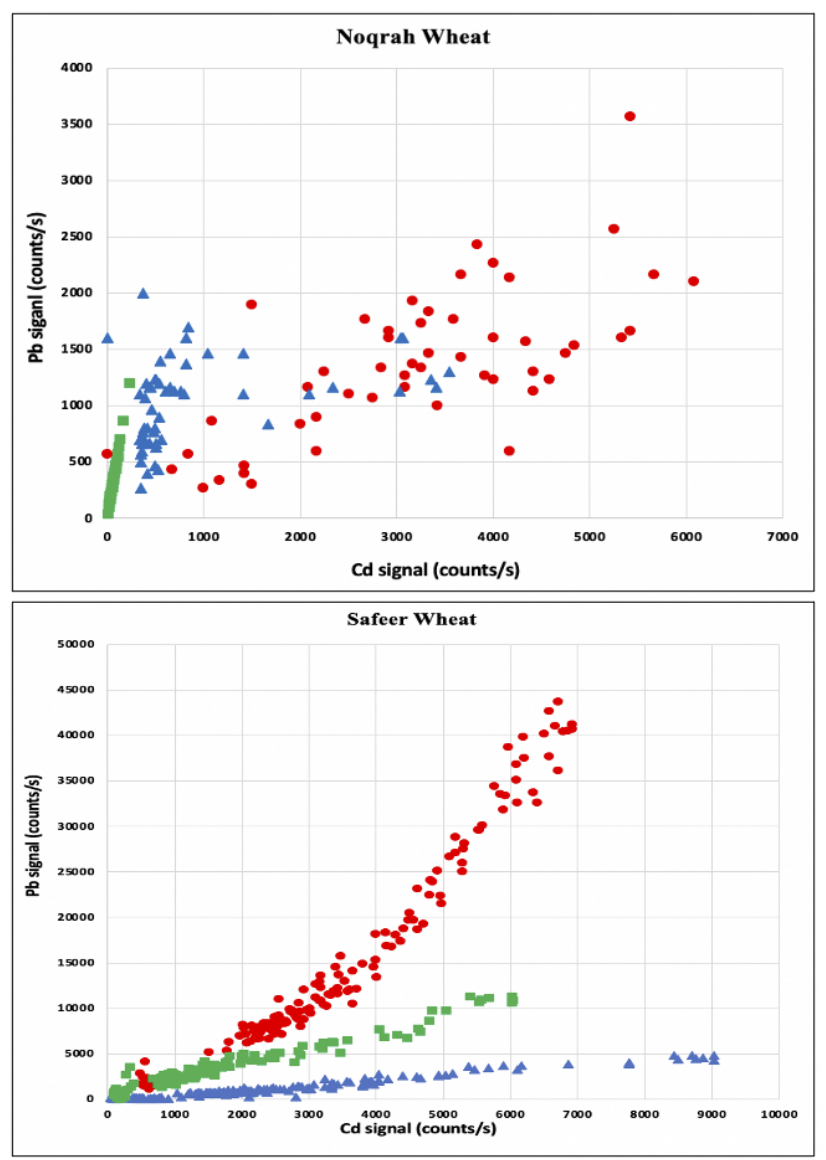

Fig. 2 Correlation between the leaching profiles of $\mathrm{Pb}$ and $\mathrm{Cd}$ with artificial saliva (blue triangles), gastric juice (red circles) and intestinal fluid (green squares) in Noqrah wheat (top) and Safeer wheat (bottom).

polluted Miswak toothbrush and Miswak fruit. Again, there is good agreement between the batch and the on-line leaching methods according to a Student's $t$-test at the $95 \%$ confidence level. The precision of ratios with the on-line method, 1-5\% RSD, is again in general better than the $1-18 \%$ RSD with the batch method. For unpolluted Miswak toothbrush and Miswak fruit, the three ratios are similar to those measured in Saudi Arabia's western $\mathrm{Pb}$ ores (1.12-1.15). ${ }^{30}$ Moreover, ${ }^{206} \mathrm{~Pb} /{ }^{207} \mathrm{~Pb}$ values for unpolluted Miswak toothbrush and Miswak fruit are not statistically different from each other, which is commensurate with their being collected from the same tree. However, the significantly higher ${ }^{206} \mathrm{~Pb} /{ }^{207} \mathrm{~Pb}$ isotopic ratio for polluted Miswak toothbrush in the gastric phase indicates an anthropogenic source of $\mathrm{Pb}$ that corresponds to leaded petrol (with a ${ }^{206} \mathrm{~Pb} /{ }^{207} \mathrm{~Pb}$ isotopic ratio of 1.21). ${ }^{33}$ Although at least two different sources of $\mathrm{Pb}$ were indicated by the correlations between the $\mathrm{Pb}$ and $\mathrm{Cd}$ temporal profiles in each leaching reagent, ${ }^{16}$ these results were unexpected, given that leaded gasoline was discontinued in 2001. However, they support reports of leaded gasoline being mixed with unleaded gasoline. ${ }^{36-37}$ In any case, exposing a Miswak toothbrush to emissions from vehicular traffic for only a few days was clearly sufficient for it to become contaminated with a different source of $\mathrm{Pb}$.
Table 3. ${ }^{206} \mathrm{~Pb} /{ }^{207} \mathrm{~Pb}$ isotopic ratio \pm standard deviation (\% RSD) measured in saliva, gastric juice and intestinal fluid leachates from natural toothbrush samples by on-line continuous leaching and the batch method, with Student's $t$-test at the $95 \%$ confidence level $(n=3-5)$

\begin{tabular}{|c|c|c|c|c|c|}
\hline $\begin{array}{l}\text { Miswak } \\
\text { Samples }\end{array}$ & Reagent & Method & $\begin{array}{l}\text { Pb ratio }( \pm \text { SD) } \\
\text { (RSD) }\end{array}$ & $\begin{array}{l}\text { Student's } t \\
\text { Found }\end{array}$ & Table \\
\hline \multirow{3}{*}{ Unpolluted } & Saliva & $\begin{array}{l}\text { Batch } \\
\text { On-line }\end{array}$ & $\begin{array}{l}1.15 \pm 0.02(2) \\
1.15 \pm 0.02(2)\end{array}$ & 0.22 & 2.45 \\
\hline & Gastric juice & $\begin{array}{l}\text { Batch } \\
\text { On-line }\end{array}$ & $\begin{array}{l}1.11 \pm 0.08(7) \\
1.12 \pm 0.02(2)\end{array}$ & 0.40 & 2.36 \\
\hline & $\begin{array}{l}\text { Intestinal } \\
\text { fluid }\end{array}$ & $\begin{array}{l}\text { Batch } \\
\text { On-line }\end{array}$ & $\begin{array}{l}1.15 \pm 0.04(4) \\
1.15 \pm 0.06(5)\end{array}$ & 0.09 & 2.57 \\
\hline \multirow{3}{*}{ Polluted } & Saliva & $\begin{array}{l}\text { Batch } \\
\text { On-line }\end{array}$ & $\begin{array}{l}1.16 \pm 0.03(3) \\
1.15 \pm 0.02(2)\end{array}$ & 0.37 & 2.57 \\
\hline & Gastric juice & $\begin{array}{l}\text { Batch } \\
\text { On-line }\end{array}$ & $\begin{array}{l}1.21 \pm 0.22(18) \\
1.22 \pm 0.04(3)\end{array}$ & 0.04 & 2.31 \\
\hline & $\begin{array}{l}\text { Intestinal } \\
\text { fluid }\end{array}$ & $\begin{array}{l}\text { Batch } \\
\text { On-line }\end{array}$ & $\begin{array}{l}1.14 \pm 0.08(7) \\
1.14 \pm 0.02(2)\end{array}$ & 0.06 & 2.45 \\
\hline \multirow{3}{*}{ Fruit } & Saliva & $\begin{array}{l}\text { Batch } \\
\text { On-line }\end{array}$ & $\begin{array}{l}1.14 \pm 0.02(2) \\
1.14 \pm 0.01(1)\end{array}$ & 0.46 & 2.77 \\
\hline & Gastric juice & $\begin{array}{l}\text { Batch } \\
\text { On-line }\end{array}$ & $\begin{array}{l}1.13 \pm 0.01(1) \\
1.12 \pm 0.02(2)\end{array}$ & 1.26 & 2.77 \\
\hline & $\begin{array}{l}\text { Intestinal } \\
\text { fluid }\end{array}$ & $\begin{array}{l}\text { Batch } \\
\text { On-line }\end{array}$ & $\begin{array}{l}1.11 \pm 0.01(1) \\
1.12 \pm 0.02(2)\end{array}$ & 1.21 & 2.57 \\
\hline
\end{tabular}

Table 4. ${ }^{208} \mathrm{~Pb} /{ }^{206} \mathrm{~Pb}$ ratio \pm standard deviation ( $\%$ RSD) measured in gastric juice leachates from Safeer wheat and polluted Miswak samples by on-line continuous leaching and batch methods, with Student's $t$-test at the $95 \%$ confidence level $(n=3-5)$.

\begin{tabular}{lcccc}
\hline Sample & Method & Pb ratio $( \pm$ SD) (RSD) & \multicolumn{2}{c}{ Student's $t$} \\
& & & Found & Table \\
\hline \multirow{2}{*}{ Safeer wheat } & Batch & $2.05 \pm 0.07(3)$ & 0.59 & 3.18 \\
& On-line & $2.07 \pm 0.04(2)$ & & \\
Polluted Miswak & Batch & $2.04 \pm 0.12(6)$ & & 2.31 \\
& On-line & $2.06 \pm 0.04(2)$ & & \\
TEL & & 2.05 & & \\
\hline
\end{tabular}

Confirmation of TEL as a source of $\mathrm{Pb}$ in wheat and polluted Miswak toothbrush. To confirm that TEL was a source of $\mathrm{Pb}$ in Safeer wheat and polluted Miswak toothbrush, and rule out any potential spectroscopic interference that might have spuriously increased ${ }^{206} \mathrm{~Pb} /{ }^{207} \mathrm{~Pb}$, the ${ }^{208} \mathrm{~Pb} /{ }^{206} \mathrm{~Pb}$ isotopic ratio, was also measured in the gastric juice fraction. The results are summarized in Table 4 and clearly confirm TEL as a source of $\mathrm{Pb}$. Again, there was no significant difference between the ratios obtained by the batch and on-line methods according to a Student's $t$-test at the 95\% confidence level. The on-line method again provided more precise ratios than the batch method. Given that this $\mathrm{Pb}$ source appeared on Miswak toothbrush after only a few days of exposure on the side of a busy road, it also indicates the continued use of TEL in gasoline. 


\section{CONCLUSIONS}

For the first time, the ${ }^{206} \mathrm{~Pb} /{ }^{207} \mathrm{~Pb}$ isotope ratio was successfully used as a fingerprinting tool on the bio-accessible fractions from wheat, Miswak toothbrush and Miswak fruit samples from Saudi Arabia. In addition to geogenic $\mathrm{Pb}$, anthropogenic $\mathrm{Pb}$ from leaded petrol, coal combustion and other industrial sources were identified in bio-accessible $\mathrm{Pb}$. Anthropogenic $\mathrm{Pb}$ thus remains a significant pollutant, which may pose a potential risk to human health. The on-line leaching method affords visual confirmation of different $\mathrm{Pb}$ sources through the significantly different correlations that then result between the temporal profiles of $\mathrm{Pb}$ and $\mathrm{Cd}$. Future $\mathrm{Pb}$ monitoring programs could use this approach to assess whether $\mathrm{Pb}$ mitigation strategies are being effective.

\section{AUTHOR INFORMATION}

\section{Corresponding Author}

*D. Beauchemin

E-mail address: diane.beauchemin@queensu.ca

\section{Notes}

The authors declare no competing financial interest.

\section{ACKNOWLEDGMENTS}

The authors gratefully acknowledge the financial support of the Saudi Arabian Government and the Natural Sciences and Engineering Research Council of Canada (RGPNM 39487-2018).

\section{REFERENCES}

1. B. Eldering, G. Amund, H. Kunzendorf, and E. J. Krogstad, Appl. Geochem., 2002, 17, 493-502. https://doi.org/10.1016/S0883-2927(01)00119-6

2. H. M. Xu, J. J. Cao, K. F. Ho, H. Ding, Y. M. Han, G. H. Wang, J. C. Chow, J. G. Watson, S. D. Khol, J. Qiang, and W. T. Li, Atmos. Environ., 2012, 46, 217-224. https://doi.org/10.1016/j.atmosenv.2011.09.078

3. L. S. J. Tsuji, B. C. Wainman, I. D. Martin, C. Sutherland, J. P. Weber, P. Dumas, and E. Nieboer, Sci. Total Environ., 2008, 393, 291-298. https://doi.org/10.1016/j.scitotenv.2008.01.022

4. X. Y. Bi, Z. G. Li, S. X. Wang, L. Zhang, R. Xu, J. L. Liu, H. M. Yang and M. Z. Guo, Environ. Sci. Technol., 2017, 51, 13502-13508. https://doi.org/10.1021/acs.est.7b04119

5. H. Cheng and Y. Hu, Environ. Pollu., 2010, 158, 1134-1146. https://doi.org/10.1016/j.envpol.2009.12.028
6. E. Schnyder, M. Štrok, Z. Kosonen, M. Skudnik, D. Mazej, Z. Jeran, and L. Thöni, Ecol. Indi., 2018, 95, 250-259. https://doi.org/10.1016/J.ECOLIND.2018.06.072

7. L. J. Binkowski, W. Meissner, M. Trzeciak, K. Izevbekhai, and J. Barker, Chemosphere, 2016, 164, 436-442. https://doi.org/10.1016/j.chemosphere.2016.08.120

8. W. H. Shetaya, E. R. Marzouk, E. F. Mohamed, M. Elkassas, E. H. Bailey, and S. D. Young, Sci. Total Environ., 2018, 618, 460-468. https://doi.org/10.1016/j.scitotenv.2017.11.040

9. M. Tarzia, B. de Vivo, R. Somma, R. A. Ayuso, R. A. R. McGill, and R.R. Parrish, GEEA., 2002, 2, 45-56. https://doi.org/10.1144/1467-787302-006

10. WHO. Initiating an alliance for action: Healthy environments for children. Geneva: World Health Organization, 2002. https://apps.who.int/iris/bitstream/handle/10665/67382/WHO_SDE _PHE_02.06.pdf?sequence $=1$

11. H. M. Aburas, M. A. Zytoon, and M. I. Abdulsalam, Clean Soil, Air, Water, 2001, 39, 711-719. https://doi.org/10.1002/clen.201000510

12. G. E. El-Desoky, M. A. M. Aboul-Soud, Z. A. Al-Othman, M. Habila, and J. P. Giesy, Environ. Geochem. Health, 2014, 36, 583-593. https://doi.org/10.1007/s10653-013-9582-3

13. S. Mahboob, H. F. A. Albalawi, F. Almisned, S. Al-quraishy, and Z. Amhad., B. Environ. Contam. Toxicol., 2014, 92, 61-66. https://doi.org/10.1007/s00128-013-1139-8

14. H. Mohamed, P. I. Haris, and E. i. Brima, Int. J. Environ. Res. Public Health, 2017, 14, 1575. https://doi.org/10.3390/ijerph14121575

15. R. A. Althobiti and D. Beauchemin, J. Anal. At. Spectrom., 2018, 33, 642-648. https://doi.org/10.1039/C8JA00047F

16. R. A. Althobiti and D. Beauchemin, J. Anal. At. Spectrom., 2021, 36, 535-539. https://doi.org/10.1039/D0JA00479K

17. R. Larcher, G. Nicolini and P. Pangrazzi, J. Agric. Food Chem., 2003, 51, 5956-5961. https://doi.org/10.1021/jf021064r

18. E. Margui, M. Iglesias, I Queralt and M. Hidalgo, Sci. Total Environ., 2006, 367, 988-998. https://doi.org/10.1016/j.scitotenv.2006.03.036

19. C. J. Lord, J. Anal. At. Spectrom., 1994, 9, 599-603. https://doi.org/10.1039/JA9940900599

20. Y. Yaffe, C.P. Flessel, J. J. Wesolowski, A. del Rosario, G. N. Guirguis, V. Matias, J. W. Gramlich, W. R. Kelly, T. E. Degarmo, and G. C. Coleman, Arch. Environ. Health, 1983, 38, 237-245.

21. F. Liang, G. L. Zhang, M. G. Tan, C. H. Yan, X. L. Li, Y. Li, Y. M. Zhang, and Z. C. Shan, Environ. Sci. Technol., 2010, 44, 4760-4765. https://doi.org/10.1021/es9039665

22. S. Z. Cao, X. L. Duan, X. G. Zhao, B. B. Wang, J. Ma, D. L. Fan, C. Y. Sun, B. He, F. S. Wei, and G. B. Jiang, Environ. Int., 2014, 73, 158-166. https://doi.org/10.1016/j.envpol.2014.12.035

23. L. Nijhawan, M. Janodia, B. Muddukrishna, K. Bhat, K. Bairy, N. Udupa and P. Musmade, J. Adv. Pharmaceut. Technol. Res., 2013, 3, 134-140. https://doi.org/10.4103/2231-4040.116779

24. M. Chu and D. Beauchemin, J. Anal. At. Spectrom., 2004, 19, 1213-1216. https://doi.org/10.1039/b403215b

25. M. Chu and D. Beauchemin, Can. J. Anal. Sci. Spectrosc., 2005, 50, 289-296. https://doi.org/10.17104/0017-1417_2010_5_424

26. R. A. Althobiti, and D. Beauchemin, J. Anal. At. Spectrom., 2021, 36, 622-629. https://doi.org/10.1039/D0JA00447B

27. https://www.globalsecurity.org/jhtml/jframe.html\#https://www.globa lsecurity.org/military/world/gulf/images/map-saudiindustry.jpg||Saudi\%20Arabia\%20Industry\%20Map, Accessed March 10, 2021. 
28. V. N. Epov, S. Berail, M. Jimenez-Moreno, V. Perrot, C. Pecheyran, D. Amouroux, and O. F. X. Donard, Anal. Chem., 2010, 82, 5652-5662. https://doi.org/10.1021/ac100648f

29. R. M. Ellam., Sci. Total Environ., 2010, 408, 3490-3492. https://doi.org/10.1016/j.scitotenv.2010.03.037

30. I. A. Al-Saleh, C. Fellows, T. Delves, and A. Taylor, Ann. Clin. Biochem., 1993, 30, 142-145. https://doi.org/10.1177/000456329303000205

31. M. Díaz-Somoano, M. E. Kylander, M. A. Lopez-Anton, I. S. U. Arez-Ruiz, M. R. Martinez-Tarazon, M. Ferrat, B. Kober, and D. J. Weiss, Environ. Sci. Technol., 2009, 43, 1078-1085. https://doi.org/10.1021/es801818r

32. https://www.abarico.it/03-22218/ZFrpl.html, Accessed February 27, 2021.

33. J. S. Stacey, B. R. Doe, R. J. Roberts, M. H. Delevaux, and J. W. Gramlich, Contrib. Mineral. Petrol., 1980, 74, 175-188. https://doi.org/10.1007/BF01132003
34. A. Bollhofer and K. J. Rosman. Geochim. Cosmochim. Acta, 2001, 65, 1727-1740. https://doi.org/10.1016/S0016-7037(00)00630-X

35. S. Kumar, S. G. Aggarwal, J. Malherbe, J. P. G. Barre, S. Berail, P. K. Gupta, and O. F. X. Donard, Atmos. Environ., 2016, 132, 179-187. https://doi.org/10.1016/j.atmosenv.2016.03.002

36. https://www.al-jazirah.com/2004/20040104/ec10.htm, Accessed April 26, 2021.

37. https://www.al-jazirah.com/2001/20010210/rv5.htm, Accessed April 26, 2021.

38. A. M. Scheuhammer and D. M. Templeton, Ecotoxicol., 1998, 7, 37-42. https://doi.org/10.1023/A:1008855617453

39. A. M. Scheuhammer, D. E. Bond, N. M. Burgess, and J. Rodrigue, Environ. Toxicol. Chem., 2003, 22, 2585-2591. https://doi.org/10.1897/02-361

40. M. M. Larsen, J. S. Blusztajn, O. Andersen, and I. Dahllöf, $J$. Environ. Monit., 2012, 14, 2893-2901. https://doi.org/10.1039/c2em30579h 